\title{
New Paradigm of Effective e-Learning through System Development Life Cycle Structure
}

\author{
Saeed Qasim Y. Al-Khalidi
}

\begin{abstract}
The emergence of e-learning has created a considerable increase in the number of virtual universities worldwide. A global education system, as a key area of the future of ICT, has encouraged developers to provide various low cost learning systems. An increase in the number of Saudi universities, combined with the large number of internet users in Saudi Arabia, has provided a number of benefits to students at university level. The system development life cycle (SDLC) model proposed in this paper is tailored towards the e-learning environment, particularly in Saudi Arabian universities. The paper will also attempt to provide suggestions and possible solutions to implementing e-learning methods effectively. The objective of this paper is to present a model of a web services-based e-learning life cycle which defines all the necessary functionality for interactions between the learning centre and the learner. However, real progress in terms of designing new learning styles based on quality learning materials can be evaluated only over the long term.
\end{abstract}

Index Terms-E-learning, system development life cycle, online education, e-learning centre.

\section{INTRODUCTION}

E-learning is inclusive of, and is broadly synonymous with, multimedia learning, technology-enhanced learning, computer-based training, computer-assisted instruction, Internet-based training, web-based training, online education, virtual education, virtual learning environments, e-learning, and digital educational collaboration [1], [2]. These alternative names each emphasise a particular aspect, component or delivery method of e-learning. Teacher-student interaction within this can take place using voice, video, data and print.

The use of computers and the Internet has long been advocated by educators who seek to apply a learner-centred constructivist model through the use of technology [3]. In a computer-supported environment, time and space are no longer constraints to learning; students can work collaboratively on projects either synchronously or asynchronously, whether in the classroom, at home, or anywhere else, as long as they have access to the Internet [4].

Moreover, as the Net-generation grows up in a world dominated by digital devices, electronic communications, constant multimedia exposure, and the Internet, the expectation is that these tools and resources will be employed in teaching and learning as well. With the advent of multimedia and other new technologies, teachers could enable their students to learn in more productive ways [5].

Manuscript received September 10, 2013; revised November 13, 2013.

The author is with the Department of Management Information Systems, College of Administrative and Financial Sciences, King Khalid University (KKU), KSA (e-mail: salkhalidi@kku.edu.sa).
The importance of utilising such technologies is supported by research which suggests that people remember $75 \%$ better when they receive information through audio-visual media, rather than through hearing or seeing the same information separately [6].

In 2008, the KSA Ministry of Higher Education established a National Centre of E-Learning and Distance Learning in order to promote and facilitate the spread of e-learning systems in Saudi universities. E-learning is still in its infancy in Saudi Arabia [7]. So far, the emphasis has been on improving the use of information technology in curriculum and resource development, and establishing electronic communities. In this regard, a project has been launched to connect schools and educational directorates by means of a wide area network covering the entire country [8]. Some of the reasons given by students for choosing to learn through an e-learning centre are reported below:

- To help achieve a promotion within an organisation

- To obtain a higher degree

- To improve skills

- Revision

- To experiencing e-learning

- For computer studies

- To learn from home

- To study a course not available in universities

- No university/college near home

This paper presents a course design model for second language learning that is distinct from the traditional instructional model. It creates a constructive learning environment that focuses on the learner as the centre of the learning process, where active learning takes place with the aid of computer technology learning materials and resources. The basic idea is to identify how interoperability between existing systems can be advanced using web services. Common services, essential for the creation and authoring stages of a typical e-learning system and its lifecycle have been identified and created [9].

\section{BACKGROUND LITERATURE}

In a co-authored paper, Syed Hussain Ali, Sadiq M. Sait and Khalid M. Al-Tawil [8] have analysed perceptions of e-learning in Saudi Arabia. In this study, it was discussed whether the Saudi Arabian education system is under stress to provide additional educational opportunities for the increasing population, along with their desire to increase the literacy rate. The capacity growth rate of existing Saudi educational institutes does not match the current growth rate of enrolment demand. In the study mentioned above, user perceptions about distance learning were reported. These responses were part of a broader study that concerned the use 
and effect of the Internet in Saudi Arabia.

Elsewhere, Abbad M. Alabbad [9] has discussed interactive computer/network-based programmes for teaching English as a foreign language at elementary level in Saudi Arabia. In this research article, the author discussed the way in which the use of computers and the Internet has long been advocated by educators who seek to apply a learner-centred constructivist model through the use of technology.

Balarabe Yushau, meanwhile [10] has conducted a survey on the influence of blended e-learning on students' attitudes towards mathematics and computers. A random sample of 70 students from the preparatory year programme of the King Fahd University of Petroleum \& Minerals (KFUPM) were surveyed. The result indicates that the subjects had positive attitudes towards mathematics and computers.

Finally, Aroyo and Dicheva [11] have discussed new challenges for e-learning. Their article outlines the current state of research on that topic, and suggests a realistic approach towards the Educational Semantic Web. With regard to the latter issue, a modular semantic-driven and service-based interoperability framework is proposed in order to open up, share and reuse the educational system's content and knowledge components.

\section{Statement OF ReSEARCH PROBLEM}

Changes in technology have accelerated the growth of e-learning and improved access and availability of electronic technology has enabled more students to participate in the learning process. Centres of learning must consider course standards, curriculum development and support, course content, and course pacing when developing e-learning programmes.

If distance courses are to receive the respect they deserve, curriculum and assessment materials must be developed to an equal standard to those of a traditional classroom. The course content, learning objectives, standards, and credits for all aspects of the course must be maintained, regardless of the method of delivery [12].

Course content can affect student persistence with e-learning, as some kinds of coursework are more conducive to distance classes than others [12]. Poorly designed course materials are key contributors to student attrition rates. Course content itself cannot, therefore, be ignored in any theoretical or practical consideration regarding distance education attrition. It is necessary to concentrate on the following factors during the implementation phase of effective e-learning:

- Centre facilities

- Online facilities

- Supporting materials

- Feedback options

- Theory and practical link

- Questioning

\section{PROPOSED SDLC STRUCTURE}

The tendency in e-learning is to design courses focused on information. These tend to be click-and-read courses, where the learner simply clicks a 'next' button to advance. Ideally, however, an e-learning course should be less about the information and more about how the learner uses the information. This helps keep the course meaningful and relevant [13].

Within the System Development Life Cycle (SDLC), the structure of an e-learning course provides the necessary foundation for quality content, delivery and service. Establishing the structure includes anticipating learner needs, using appropriate pedagogical strategies, creating a positive learning environment, and conducting regular learner evaluations. The delivery of an e-learning course includes considerations regarding usability, interactivity, and providing the correct tools for learners and educators [14]. The content of an e-learning course should be comprehensive, authentic, and thoroughly researched. Services necessary for running an e-learning course include resources, administration, technical support, accessibility, and responsiveness. Finally, the outcomes of an e-learning course should include lower costs for the learner and the employer, personal advantages, and the achievement of learning outcomes [14]. Various aspects of the SDLC structure (see Fig. 1) proposed to meet these needs are presented below.

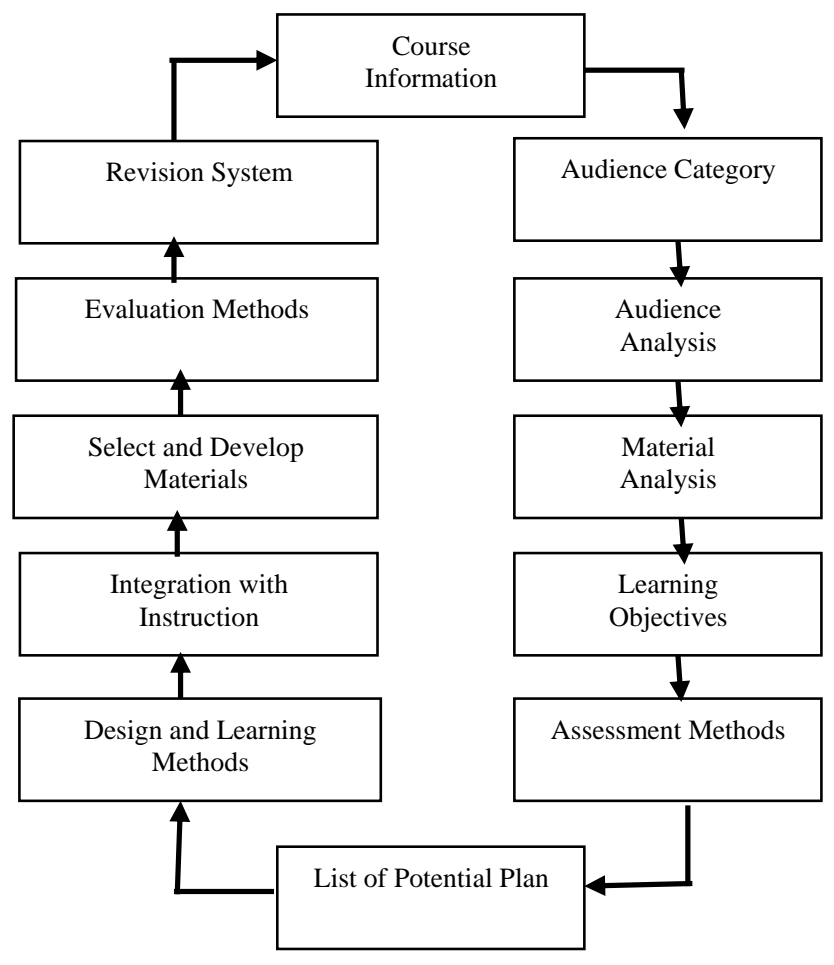

Fig. 1. SDLC structure.

\section{A. Course Information}

The terms "course information" refers to how a course is designed to be engaged with via e-learning processes. The course information plays a critical role in how the audience selects and learns from the courses they study. During the design phase, the course should be organised and the flow of the course should be identified in order to determine how to modulate the information presented. It is good practice to include images, whenever possible.

\section{B. Audience Category}

It is very important to classify the categories to which 
e-learners belong. There are many categories of e-learner, such as students, housewives, employees, professionals and children. It is thus important to prepare course content, materials and interactions to best suit the audience category at which they are aimed. Knowledge of the audience category will help to identify the abilities of the audience for which course materials are being prepared.

\section{Audience Analysis}

This is one of the most commonly overlooked areas when learning about the audience for e-learning programmes. The audience will always have a preference as to how they learn. Knowledge of the audience's preferred learning styles will help in the designing a course that is both interactive and that can achieve results. Analysing the learner will assist in meeting the expectations and objectives of e-learners. Furthermore, this knowledge will help in the creation of effective online exercises and interactions to help the learner grasp the subject presented.

\section{Material Analysis}

Most e-learning centres fail to prepare effective course material and content. The balance between text and graphics in the course material is critical. Text, for example, should not be overpowered by excessive use of graphics or images. Keeping objects and fonts consistent throughout the course material may also help prevent the learner from becoming frustrated in the course of their training. Organising concepts and topics using bullet points or numbers helps improve learners' information retention and also helps the learner to quickly find key points or critical facts within course material Chunking information into small pieces will also help the audience retain information presented during training.

\section{E. Learning Objectives}

The objectives of the e-learning should match the expected outcomes of the training or course that is being developed. Questions such as, "What will be required of the learner after completing the course or training?" and, "What skill level is required to be certified or qualified upon completing the course or training?" should be considered. Knowledge of these expectations will help when determining the structure, content, and format of the course or training programme.

\section{F. Assessment Methods}

The assessment method is self-checking of the e-learning environment. This allows the learner to verify that they have understood the content, while at the same time provides a means by which the instructional designer can verify that the materials achieve the desired training objectives. The assessment method should be convenient for the learners, since everyone learns differently. It is thus advisable to allow the learner to choose from a range of option in order to find an assessment method that best meets his or her specific learning needs.

\section{G. List Potential Plan}

The potential of e-learning is very important. A good potential system can produce great results by decreasing costs and improving performance. Also, unlike a one-off classroom session, e-learning courses are available for others to use at different times and in different places. This includes static e-learning courses, as well as any on-going conversations taking place in networked communities. The following list of potential factors should be taken in to account in order to produce an effective e-learning system: decreased material costs; increased productivity; standardisation; on-going access to resources; knowledge management; ways to encourage sharing; employer of choice; real-time access; freedom to fail; improved retention; personalised learning, etc.

\section{H. Design and Learning Methods}

Similar to the way in which the charm and charisma of a classroom instructor can influence students' willingness to learn, the page design of an online course is critical to the learning process. The way a page is designed can have a huge impact on the learning experience of the audience. When creating a course, the inclusion of fun activities, such as games or other methods of interactive learning, should be considered, as people can maintain their interest in the topic for longer when they enjoy the learning experience.

\section{Integration of with Instruction}

Courses designed to lead to an accreditation or certificate give employees a tangible goal that benefits them, as well as their employer. Perhaps the best way to motivate an audience is to ensure the e-learning courses that are developed are visual and very appealing to the eye. A real time experience or story is a powerful tool in motivating an audience, since this helps students to see why something is relevant to their experience, by making it more concrete for them. When students experience problems when using the e-learning courses, access to technical support services must exist. Live chats, auto-help buttons, emails and discussion boards are some examples of support that could be offered. Ready availability of e-learning tutors and facilitators will also make students feel that they are supported in the programme.

\section{J. Selection and Development of Course Materials}

The term "content engagement" refers to the way in which the learner interacts with the content of the course. The learning material should be prepared with incorporated interactive graphics, such as animations or simulations. The purpose of the course is to instruct the learner; thus, it is important that the layout of the course material should not make it laborious for the learner to understand what he or she must do on the page. If the learning material is confusing or frustrating for the learner, they will lose interest and the learning objectives will not be achieved. As e-learning is a self-study medium, interaction with the learner is more important than with most types of training forum.

\section{K. Evaluation Methods}

One of the most oft-cited challenges involved in e-learning is the task of determining whether the course is having the intended effect. In the absence of pop quizzes and report cards, how can an employer or educational centre tell whether the implementation of e-learning is achieving its goals? The following questions can provide a focus for the effective evaluation of e-learning:

1) Did the target audience complete the course?

2) Is the course content up-to-date? 
3) Is the way information is presented easy to grasp?

4) Does the overall course meet a high standard in terms of quality?

5) Is the course inviting and visually interesting to prospective students?

6) Are the courses learner-centric?

7) Is the course easy to navigate?

8) Is the course content relevant?

9) Is the e-learning process fun and interactive?

\section{Revision System}

The method of revision used within any system should make remembering content easier, and revision activities should remain focused on the course objective. The most important factor within establishing a revision system is to never allow technology to become the main focus of the training. Technology is a tool and should be used as such in order to help people to meet the training objectives. The revision stage will engage and prepare the audience from the other competitive methods of learning.

\section{OUtCOMES OF THE PROPOSED SYSTEM}

The proposed SDLC model provides a framework for exploring the findings in more depth. Seven themes emerged from the data; these were: evaluating learning needs, implementing course materials, analysing the e-participants, analysing interactions between learners and course materials, construction of the course content, integration of support by delivery partners, and careful consideration of the benefits, drawbacks, and trade-offs involved in e-learning. Learners commented favourably on the ease of receiving and submitting materials via web services, fewer communication issues experienced, cost savings, and increased flexibility.

Convenience is one of the major advantages of e-learning. It allows students to work and learn at their own pace without the time restrictions associated with traditional learning methods. Since e-learning provides access to learning materials at any time, students have the flexibility to schedule their learning around families, jobs and other activities. This is an especially important consideration for students who wish to study in a different country. The possibility of engaging in ongoing online dialogues was also an advantage identified by many.

\section{CONCLUSION}

Many existing e-learning systems in Saudi Arabia are rated rather unfavourably by student users, due to the lack of systematic evaluation and due to the courses available using out-of-date materials. This student dissatisfaction does not stem from a lack of available technology; in fact, students are satisfied with the design of available online tools. Efforts to encourage student interaction, including requiring students to complete compulsory collaborative e-learning tasks, are thus likely to enhance the e-learning experiences of Saudi Arabian students. This study highlights the challenges of offering a quality online experience in an organisation which is still shaping an approach to e-learning. The findings suggest that the innovation and implementation of sustainable high quality e-learning courses must be part of a systematic integration of technology into the learning processes of the university.

\section{REFERENCES}

[1] S. D. Bhoite, "E-Learning: the Technology Enhanced Learning (TEL) Makes Learning Easier And Flexible," IJSR International Journal of Scientific Research, vol. 2, no. 9, pp. 84-85, September 2013.

[2] S. Rai, R. Phillips, C. C. Fung et al., "The e-learning lifecycle and its services: the Web services approach," in Proc. $2^{\text {nd }}$ International Conf. on eLearning for Knowledge-Based Society, Bangkok, 2005, pp. 4-7.

[3] P. Newhouse, "A follow-up study of students using portable computers at a secondary school," British journal of educational technology, vol. 32, no. 2, pp. 209-219, 2001.

[4] T. S. Roberts, Computer-supported collaborative learning in higher education, Hershey, PA: The Idea Group, Australia, 2005.

[5] R. Zheng and B. Zhou, "Regency effect on problem solving in interactive multimedia learning," Educational technology \& society, vol. 9, no. 2, pp. 107-118, 2006.

[6] R. Lindstrom, The Business Week guide to multimedia presentations: Create dynamic presentations that inspire, New York: McGraw-Hill, 1994.

[7] S. Alkhalaf, J. Nguyen, A. Nguyen, and S. Drew, "The potential role of collaborative learning in enhancing e-learning systems: evidence from Saudi Arabia," in G.Williams, P. Statham, N. Brown, and B. Cleland (Eds.), Changing Demands, Changing Directions, Proc. ascilite Hobart, 2011, pp. 47-58.

[8] S. Ali, S. Sait, and K. Al-Tawil "Perceptions about eLearning in Saudi Arabia," in Proc. World Conf. on Science and Technology Education, Penang, Malaysia, 2003, pp. 393-399.

[9] M. Alabbad, "Interactive computer/network-based program for teaching English as a foreign language in the elementary levels in Saudi Arabia," in Proc. International Conf. on Multimedia Computing and Systems (ICMCS), Ouarzazate, Morocco, 2011, pp. 1-4.

[10] Yushau, "The Effects of Blended E-Learning on Mathematics and Computer Attitudes in Pre-Calculus," The Montana Mathematics Enthusias TMMEt, vol. 3, no. 2, pp. 176-183, 2006.

[11] L. Aroyo and D. Dicheva, "The New Challenges for E-learning," The Educational Semantic Web. Educational Technology \& Society, vol. 7, no. 4, pp. 59-69, 2004.

[12] R. O. Falowo, "Factors impeding implementation of web-based distance learning," AACE Journal, vol. 15, no. 3, pp. 315-338, 2007.

[13] T. Kuhlmann. (2010). Roadmap for Building an E-Learning Course. Web Activity E-Learning Blog. [Online]. Available: http://www.articulate.com/rapid-elearning/a-roadmap-for-building-ane-learning-course/

[14] J. MacDonald, T. L. Thompson, and S. Content, "Delivery, Service, and Outcomes: Quality e-Learning in higher education," International Review of Research in Open and Distance Learning, vol. 6, no. 2, pp. 3, 2005.

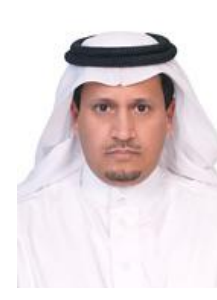

Saeed Q. Y. Al-Khalidi is the dean of Libraries Affairs at King Khalid University (KKU), Kingdom of Saudi Arabia. He published many papers in both national and international journals and has participated as a reviewer at many international conferences worldwide. Dr. Al-Khalidi completed a Masters and Doctorate (Ph.D) Degrees from England in Information Systems. His research interests include; information system development, approaches to systems analysis and the early stages of the systems development process, IT/IS evaluation practices, and e-Readiness assessment. 